Review Article

\title{
A REVIEW ON COVID-19 PANDEMIC A GLOBAL THREAT-CURRENT STATUS AND CHALLENGES AND PREVENTIVE STRATEGIES
}

\author{
SUNITHA SUKUMARAN, S. SATHIANARAYANAN*
}

Department of Pharmaceutical Chemistry and Analysis, Amrita School of Pharmacy, Amrita Vishwa Vidyapeetham, Amrita Institute of Medical Science, Amrita Health Science Campus Kochi 682041, Kerala, India

Email: sathyanarayanans@aims.amrita.edu

Received: 16 May 2021, Revised and Accepted: 28 Jul 2021

\begin{abstract}
Covid19 (Coronavirus) is a life-threatening virus that mainly affects our respiratory system, kidney, and GIT tract. People with a low immune system in their body fall prey to it. This virus (2019-nCoV) spreads easily from one person to another. As there is no treatment to kill the virus, the only way to stop this pandemic is through precautions and reduce the viral load in the body. This review reveals the main types of coronaviruses, history, pathophysiology, current treatment, drawbacks of current treatment, targets for drug development against Covid-19, vaccines discovered for covid-19, side effects of the currently available vaccines, and current status of this situation. The main mechanism of action of the virus easily enters to bind with the Angiotensin-Converting Enzyme 2 (ACE2) in the human body cells. Management of the virus several approaches will be taken mainly isolation of the patients and contacts the contacts, oxygen therapy for respiratory failure patients based on the severity Remdesivir Lopinavir/ritonavir, Chloroquine, and Hydroxychloroquine, Alpha-interferon and plasma therapy can be used to control the infections. In India, AYUSH is also recommended to enhance the immune system through herbal-based products, Vaccination is also recommended by most of the countries, but many side effects and drug-drug interactions were reported for the above treatments. So that in future a new way of approach should be developed by our health organization as soon as possible.
\end{abstract}

Keywords: Corona Virus, Treatment, Vaccines, Mutant strain virus

(C) 2021 The Authors. Published by Innovare Academic Sciences Pvt Ltd. This is an open-access article under the CC BY license (https://creativecommons.org/licenses/by/4.0/) DOI: https://dx.doi.org/10.22159/ijap.2021v13i5.42070. Journal homepage: https://innovareacademics.in/journals/index.php/ijap

\section{INTRODUCTION}

Viruses are infectious agents that replicate only inside the body. There are different kinds of viruses such as chickenpox virus, herpes virus, adenovirus, etc [1]. In many ways, a virus can spread. The main ways are transmission from plant to plant through insects, transmission by coughing and sneezing, fecal-oral route transmission, and transmission by sexual contact [2]. Among these, coronavirus, which belongs to the Coronoviridae family and Orthocoronavirinae subfamily, is the most likely to get infected in mammals and birds which have a single-stranded RNA genome [3]. In the 1930s the first coronavirus was identified. It was noticed when the domesticated chicken was affected by the acute respiratory infection that is caused by the contagious bronchitis virus (IBV). In the 1960s, the human coronavirus was discovered. The main symptoms were common cold, fever, and breathing difficulty. Later this was named human coronavirus 0C43 and human coronavirus 229E [4]. The word corona came from the Latin word, corona which means crown. It has the structure of large spherical pleomorphic particles with bulbous surface projections. $120 \mathrm{~nm}$ is the average diameter of a coronavirus. The main mechanism of entry of virus to the host cell is the attachment of (s) glycoprotein of the virus-cell to the host cell receptor. After attaching to the receptor, the protease of the host cell cleaves and activates the receptor attached glycoprotein. The main portion for the host cell attachment is the 5-methylated cap and 3polyadenylated tail, which helps for translation. There are a total of six coronaviruses are available. In that, one is divided into two. So a total of seven are available. Those are Human coronavirus OC43, HKU1, 229E, NL63, MERS-related coronavirus, severe acute respiratory syndrome coronavirus, SARS CoV 2 [5]. In the Wuhan city of china, the Coronavirus disease 2019 was first reported and named as SARS-CoV-2. The world health organization has to develop updates on the current status of this infection and its health measures [6].

\section{Search criteria}

The information was gathered using a methodical strategy that began with studying pathophysiology and targets identified for the SARS CoV 2 from high-quality publications. More than 200 articles were searched and identified, and 61 important types of literature were chosen from the huge corpus of COVID-19 publications. This review included the article from 1995 to 2021 and the data related to the review topic was collected from the various databases PubMed, Science Direct, and Google Scholar by using the search words: SARS Cov2, pathophysiology, Current treatment strategy, Vaccines, herbal studies in Covid and new strains of Corona Viruses.

\section{History}

In 2003 in Hong Kong, fifty patients were affected by severe acute respiratory syndrome (SARS) in the age group of 23 to 74 with the symptoms of fever, myalgia, and cough. The liver dysfunction patients with older age groups were found to be more severe compared to other people. In Saudi Arabia, in the year 2014 had MERS-CoV a high mortality rate in the age group of 65 and greater than 65. They did not show any symptoms in the early stage [7].

\section{Epidemiology and pathophysiology}

A high mortality rate was found in these coronavirus diseases. From that $34.4 \%$ death rate was found in MERS-CoV and other percentages of disease death were unknown [8,9]. As per the latest report of WHO published in April 2021, globally confirmed cases of Covid-19 were 147,539,302. 3,116,444 deaths were confirmed by the World Health Organization (WHO). Infection begins with membrane fusion attachment and the RNA genome is used as a template after un-coating to utilize the synthesize of genomes of the progeny and a nested collection of RNA sub genomics [10]. The replication transcription centers are closely associated with DMVs which are proposed to be adopted from the modified ER, probably through the combined activities of nsp3, nsp4, and nsp6 nonstructural proteins [11]. The proteins E, M, and S are prepared and anchored on the ER, while the protein $\mathrm{N}$ is translated into the cytosol. Assembly takes place in the ERGIC, and exocytosis releases mature virions through smooth-walled vesicles. The three stages that presumably induce ER stress are illuminated with numbered star signs, namely: (1) DMV formation, (2) major structural protein development and alteration, and (3) depletion of ER membrane during budding $[12,13]$. The virus that lives in the host cell is picturized in fig. 1 . 


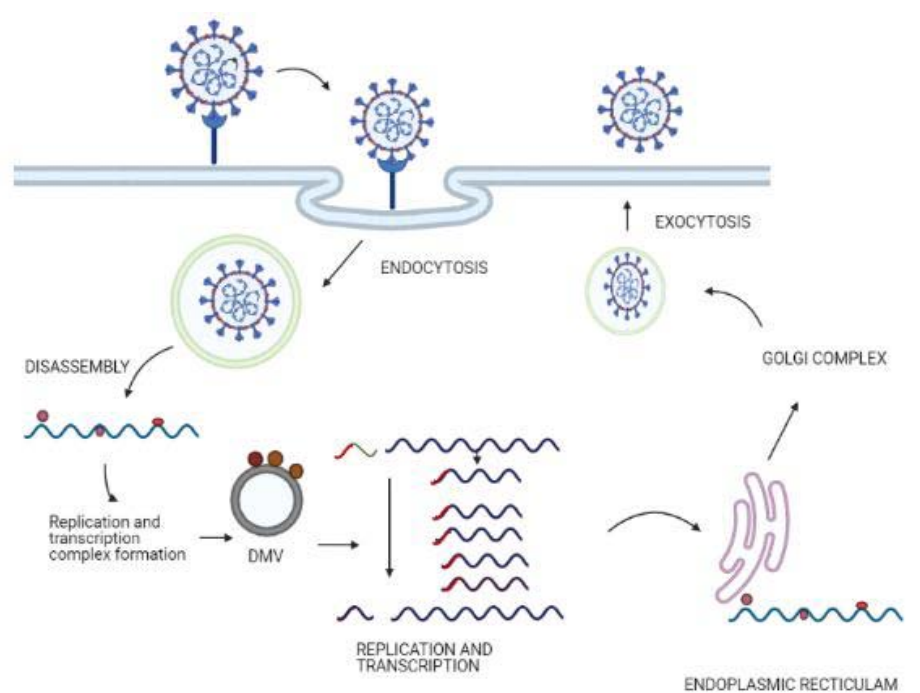

Fig. 1: Virus life cycle in the host cell

\section{Treatment for covid-19}

Several antiviral agents are available for many viral infections. During the corona outbreak there was no treatment available; later Chloroquine Phosphate by oral administration was recommended for this disease $[14,15]$. For older patients whose body weight is more than $50 \mathrm{~kg}$, Chloroquine phosphate $500 \mathrm{mg}$ is given orally. For those with a bodyweight of $50 \mathrm{~kg}$ or less, it is recommended to bid $500 \mathrm{mg}$ on the 1 st and 2 nd days, and $500 \mathrm{mg}$, four times in a day (q. i. d) on the 3rd to 7th days, with a 7-day course of treatment. The only FDAapproved drug for treating Covid-19 is Remdesivir. It is an anti-viral agent belonging to the non-nucleoside analogues class, used to prevent viral RNA synthesis. It is administered at a dose of $100 \mathrm{mg}$ vial. Later, patients with severe pneumonia conditions were administered with Dexamethasone, belonging to the corticosteroid class. The drug is administered orally or intravenously at a dose of $6 \mathrm{mg}$ once daily for $10 \mathrm{~d}$ but less benefited to non-severe pneumonia patients. It modulates immune-mediated lung injury and cuts the risk of death in patients on ventilators. But Dexamethasone is not approved in India. Adult patients hospitalized with confirmed SARS-COV-2 infection were provided with Lopinavir/ritonavir combination drug at a dose of 400 $\mathrm{mg}$ and $100 \mathrm{mg}$, respectively, twice a day for $14 \mathrm{~d}$. It is an HIV protease inhibitor used to prevent polyprotein proteolysis. The dosage of the drug mainly depends on the patients' medical condition and for children, the approach of the drug is through the patient's body weight and height. The combination lowers the mortality or SARS-COV-2 RNA level but a standard cure from the treatment is not found. Patients with elevated IL-6 levels are recommended for Tocilizumab of repeated-dose, which is an IL-6 inhibitor used to treat cytokine release syndrome. It is given intravenously at a single dose of $400 \mathrm{mg}$, which reduced inflammation, mortality, oxygen requirement, and vasopressor support. The drug is an alternative treatment for COVID19 patients with a risk of cytokine storms recently. Dapagliflozin, SGLT-inhibitor, is used in COVID-19 patients, which reduces the adults with metabolic or renal risk factors, cardiovascular complications. The goal of the trial, called DARE-19 (Dapagliflozin in Respiratory Failure in patients with COVID-19). Patients with onset of symptoms treated less than $7 \mathrm{~d}$ delivered a triple combination therapy of $14 \mathrm{~d}$ of oral lopinavir-ritonavir, every $12 \mathrm{~h}$, ribavirin $400 \mathrm{mg}$ every $12 \mathrm{~h}$, and s/c injection of one to three doses of Interferon-beta-1 b $1 \mathrm{ml}$ (8 million IU) on alternative days, people with symptom onset of day 1-2 are received all doses of Interferon-beta-1b; if start off on day 3-4; received 2 doses; if commenced on day 5-6 are received 1 dose. The patients having membrane attack complex were provided with the drug Eculizumab, the dose of $10 \mathrm{mg} / \mathrm{ml}$, which modulates the activity of distal complement [16-19].

Convalescent plasma therapy is found to be an experimental treatment and researchers are in the hope that this therapy could help patients with severe COVID-19 complications. This remedy helps the patients to boost up their ability to fight the virus and also to avoid patients being more ill and experiencing the symptoms from their moderate condition. The blood from people who've recovered is called convalescent plasma. This mechanism mainly works has the patient's Antibodies-proteins the body uses to fight off infections-to the disease in their blood. This therapy is useful to the patients with COVID-19 where other drugs haven't helped them during the treatment. The latest news for COVID-19 treatment is that a first new biologic therapy-Itolizumab which is administered at a dose of $25 \mathrm{mg} / 5 \mathrm{ml}$ injection solution to treat cytokine release syndrome (CRS) in moderate to Severe Acute Respiratory Distress Syndrome (ARDS) patients with COVID-19 [20].

\section{Drawbacks of current treatment}

Many adverse effects and drug interactions were reported for Chloroquine Phosphate. Patients having a cardiovascular problem can affect the drug controversy. Neuromuscular pain, granulocytopenia, irreversible visual impairment, itching, dermatitis, rashes also reported the remaining adverse effects. Many drug interactions were also reported by the continuous use of chloroquine phosphate. Combined use of Chlorpromazine and chloroquine phosphate leads to increased liver dysfunction. Administration of this drug after the use of digitalis causes cardiac block. The combined use of antibiotics and this drug causes an inhibitory effect of neuromuscular junction [21]. Hydroxychloroquine/chloroquine doesn't help hospitalized COVID19 patients and when used as a prophylactic drug, it failed to prevent infection. Combined use of Azithromycin and Hydroxychloroquine has not shown any clinical benefit or any known and no evidence of strong antiviral activity. Recently, WHO announced that the Solidarity trial for HCQ has stopped where the drug doesn't show any reduction in the mortality of hospitalized COVID-19 patients. In the case of, Ribavirin and Remdesivir trial studies showed that these drugs have only limited benefits. The combinational drug Lopinavir-ritonavir has shown no therapeutic effect for the treatment of severe illness caused by SARS-COV-2. The slightly affected patients weren't benefited with Tocilizumab has this drug only helped patients with a critical illness. In the case of convalescent plasma therapy, the risk of infection was low but another carrier risk was also found in the trials like allergic reactions, breathing difficulty, lung damage, and transmission of infection during the transfusion. The drugs under the Solidarity trial are mainly off-label agents for the treatment of COVID-19, such as Eculizumab drug are pending the confirmation for the remedy [22].

\section{Target identified in covid-19}

For the development of a potent therapeutic agent against covid-19, the preferred targets are mainly based on host-based targets and virus-based targets. The virus-based targets are divided into 
structural proteins and non-structural proteins; structural proteins are considered as the potential targets against covid-19, they are spike protein, Nucleocapsid protein, envelope protein, and membrane protein. There are 16 non-structural proteins such as RNA-dependent RNA polymerase, helicase, and Proteases 3CLpro. RNA-dependent RNA polymerase is a conserved protein that plays a crucial role in the virus lifecycle [23].

Another promising drug target is host-based like ACE2 host receptor in which virus entry occurs through binding to this receptor. The spike protein present in the infectious coronavirus is stimulated by the Transmembrane Serine Protease 2, a host-based receptor. Other targets based on the host are Adaptor-Associated Kinase 1 (AAK1) and Cyclin G-Associated Kinase, Phosphatidylinositol 3-Phosphate 5Kinase, and Cathepsin L.

In silico studies are done to identify the potential candidates targeting both human and viral gene/receptor/enzyme taking part in the pathogenesis of the disease. Nowadays in silico studies involving both host and viral-based targets, the main targets selecting for studies are spike protein, main protease, transmembrane protein serine, and RNA-dependent RNA polymerase [24, 25]. Many targets have been identified and some of them have undergone drug repurposing studies and are listed in table 1.

Table 1: Targets chosen for the covid-19

\begin{tabular}{|c|c|c|c|}
\hline Gene/Receptor/Enzyme & PDB ID & Organism & Reference \\
\hline \multirow[t]{2}{*}{ Papain-like protease (PLP/PLpro) } & 3E9S & SARSCoV2 & {$[26]$} \\
\hline & $5 Y 3 E$ & & [27] \\
\hline \multirow[t]{4}{*}{ 3C-like protease (3CLpro/Mpro) } & 1Z1I & SARSCoV2 & [28] \\
\hline & $5 R 82$ & & [29] \\
\hline & $2 \mathrm{Z9J}$ & & [30] \\
\hline & $6 Y 2 G$ & & [31] \\
\hline \multirow[t]{3}{*}{ RNA-dependent RNA polymerase (RdRp) } & 6NUR & SARSCoV2 & [32] \\
\hline & 7BV2 & & [33] \\
\hline & $6 N U S$ & & [34] \\
\hline Helicase & 6JYT & SARSCoV2 & [35] \\
\hline Guanine-N7 methyl transferase & $5 \mathrm{C} 8 \mathrm{~S}$ & SARSCoV2 & [36] \\
\hline Uridylate-specific endoribonuclease (Nsp15) & 6VWW & SARSCoV2 & [37] \\
\hline 2'-0-Methyltransferase & $3 R 24$ & SARSCoV2 & [38] \\
\hline ORF7a protein & $1 \mathrm{YO} 4$ & SARSCoV2 & [39] \\
\hline \multirow[t]{2}{*}{ Spike protein (S protein) } & 3SCI & SARSCoV2 & [40] \\
\hline & $6 V Y B$ & & \\
\hline Envelope protein & $5 \times 29$ & SARSCoV2 & {$[41]$} \\
\hline \multirow[t]{2}{*}{ Nucleocapsid phosphoprotein (N protein) } & 1SSK & SARSCoV2 & [42] \\
\hline & 2CJR & & \\
\hline \multirow[t]{2}{*}{ Angiotensin converting enzyme 2 (ACE 2) } & $1 \mathrm{R} 42$ & HUMAN & {$[43]$} \\
\hline & 6VW1 & & \\
\hline Transmembrane protease serine 2 (TMPRSS2) & 5CE1 & HUMAN & {$[44]$} \\
\hline AP2-associated protein kinase 1 (AAK1) & $5 \mathrm{~L} 4 \mathrm{Q}$ & HUMAN & [45] \\
\hline human furin (hFUR) protease & $5 \mathrm{JXH}$ & HUMAN & [46] \\
\hline \multirow[t]{2}{*}{ Carcinoembryonic antigen-related cell adhesion molecule 1 (CEACAM 1) } & 5YIQ & HUMAN & [47] \\
\hline & $2 Q S Q$ & & \\
\hline
\end{tabular}

\section{Herbal based studies in covid-19}

For primary health care, many countries still depend on herbal medicines, although traditional medicines are used as antiviral agents. Alkaloids, steroids, di-terpenoid lactones, and glycosides are the phytochemicals derived from the plants which have shown antiviral effects in human. Currently, many+herbal-based studies are undergoing in coronavirus disease. The herbal plant Tinospora cordifolia is used in many Ayurveda preparations for treating urinary disorders, allergic conditions, diabetes, inflammation, rheumatism, enhance the body's immune system, anemia, and skin diseases [48] Papia Chowdhury reported that berberine, the phytoconstituent present in Tinospora cordifolia has established its strong candidature to serve as potential inhibitors in regulating the 3CLpro [49]. Mansi Pandit and N. Latha stated that the compound Silybin from Silybum marianum, Catechin, and Quercetin from Aloe Barbadensis, Withaferin $\mathrm{A}$ in the Withania somnifera and Cordioside from the Tinospora cordifolia showed greater energy of binding [50]. Glycyrrhizin which is present in the root of licorice neutralizes the SARS-CoV 2 in vitro through targeting the main protease Mpro. The chemical constituent present in turmerics such as curcumin and cyclocurcumin also dihydroxy dimethoxy flavone and andrographolide from the plant Andrographis paniculata is inhibiting SARS CoV-2 main protease enzyme also many of the phytochemicals are understudies to identify the effectiveness against covid-19.

\section{Covid-19 vaccination}

During the pandemic situation, it is a challenging process to develop and scale up the process of a vaccine. Around the world, dozens of vaccines have been authorized and still many vaccines are under development. Covishield, covaxin by India are the authorized vaccines and many vaccines are in the clinical trials. For the safe and effective development of the vaccine, the design of the vaccine is mainly based on the mRNA, Adenovirus vaccine, live attenuated vaccine, etc [51,52]. The authorized vaccines are tabulated in table 2 .

Table 2: Few authorized vaccines for COVID-19

\begin{tabular}{llll}
\hline Name & Primary developer & Country of origin & Mechanism \\
\hline Covishield & Oxford University and AstraZeneca, & UK & Adenovirus vaccine \\
Comirnaty & Pfizer, BioNTech & Multinational & mRNA based vaccine \\
Covaxin & Bharat Biotech, ICMR & India & Inactivated vaccine \\
CoronaVac & Sinovac Biotech & China & Inactivated vaccine (formalin with alum adjuvant) \\
Sputnik V & $\begin{array}{l}\text { The gamaleya research institute, acellena } \\
\text { contract drug research and development }\end{array}$ & Russia & [54] \\
& & & Recombinant adenovirus vaccine (rAd26 and rAd5) \\
\hline
\end{tabular}


ZyCoV-D is a vaccine candidate in the development stage sponsored by the Zydus Cadila. ZyCoV-D is a DNA vaccine and it is in phase 3 clinical trial. $\mathrm{CVnCoV}$ is an mRNA-based vaccine developed by curevac: GSK, which is in the $2 \mathrm{~b} / 3$ phase trial. Abdala (CIGB66) a protein subunit vaccine developed by the Center for genetic engineering and biotechnology and it's in phase 3 clinical trial. Bacillus Calmette-Guerin (BCG) vaccine, INO-4800, VIR-7831, and UB-612 are the vaccines in the phase $2 \mathrm{~b} / 3$ stage.

\section{Preventive strategies}

"Prevention is better than cure" so that Preventive measures should be following the Government norms and World health Organization advise to overcome the medical emergency such as break the chain through social distancing, make awareness to wear masks like N95, Double Masking (one surgical Mask and one triple-layer Cloth Mask), maintenance of hygiene, gargling with hot water, Inhalation of a stream (with or without herbs), isolation, and movement restrictions can help in the control of COVID-19 spread. Proper sanitization and cleaning of hands can be effective in inhibiting the spread of the virus.

\section{Safety of covid-19 vaccines}

In this pandemic situation, there is an essentiality for the Covid vaccine. Many of the countries started to provide vaccines to health care workers and common people, but the side effects are reporting after receiving the vaccines. Pfizer-BioNTech vaccines urgent approval from US-FDA. E 1-shitanyNA et al. conducted a retrospective study and researched the mild to moderate effects of Pfizer BioNTech vaccines in Saudi residents. As per the European Medicines Agency (EMA) information, thromboembolic events have been reported among the recipients who received OxfordAstraZeneca COVID-19 vaccine. Moderna, the mRNA vaccine reported side effects are fatigue, joint pain, fever, and muscle pain. Still, studies are going on to find out the mild to moderate side effects and effectiveness of Covid vaccines $[55,56]$.

\section{Current status}

World Health Organization reported the current case comparison of COVID 19 at a global level. There is no cure for corona virus-infected patients. A medical electronics research unit in De Scalene Organization revealed a device that can help to neutralize the spread of coronavirus disease and it will be tested by the University of Maryland in the U. S. Dr. Rajah Vijay Kumar, Chairman of this Organization said that the device cannot have the capability to cure the patients who have already infected it can keep in houses, schools, auditorium and public places for the prevention of spreading of virus from one person to other. The mechanism he was explaining the neutralization of electrons. The virus consists of cells containing a large amount of S-proteins. These S-proteins having a highly positive charge and our body has highly negatively charged DNA $[57,58]$. So, when the virus once gets into the body, it sticks into the negatively charged cells and starts replicating. The device helps to resist this replication by neutralizing the positively charged particles. This device produces a large number of electrons and the virus attaches these electrons and neutralizes the charges because the virus doesn't know the difference between electrons in our body and the device. In such a way they are developing a large device for more resistance. The current situation of this pandemic is that, reporting mutant strains and developed unusual public health events. There are three clinically recognized mutant variants of the virus. The London variant with 23 mutations will spread rapidly and have an increased risk of death. The London variant is known as B.1.1.7 and in 2021 January the South African variant knows as B.1.351 was reported. Indian variants, London variant viruses are reporting around the world, and the Indian variant is found to be more infectious, as the vaccination campaigns are still going on in every country. The primary studies of covaxin and Covishield show that they are effective against an Indian strain of Covid-19 [59-61].

\section{CONCLUSION}

This review reveals the main types of coronavirus, history, pathophysiology, current treatment, drawbacks of current treatment, covid-19 studies based on the herbal plants which have already reported antiviral, anti-inflammatory, and immunomodulatory activities, vaccines developed for covid-19, and the side effects of vaccines, and current updates of coronavirus disease 2019. COVID 19 is a life-threatening problem, the main problem of this situation is the lack of immunity and lack of precautions. By avoiding the contact and proper progress of our immune system can overcome the virus infection. World health departments are developing new techniques day by day. Effective vaccination will fight against the covid-19 but the mutation of the coronavirus is reporting in every country, which will be a new crisis and threaten the public health care system worldwide.

\section{ACKNOWLEDGEMENT}

The authors are thankful to the Department of Pharmaceutical Chemistry and Analysis, Amrita school of pharmacy. Amrita Vishwa Vidyapeetham Kochi.

\section{FUNDING}

The authors declare that they have no funding support for this study.

\section{AUTHORS CONTRIBUTIONS}

All authors have contributed equally.

\section{CONFLICT OF INTERESTS}

The authors declare that they have no conflict of interest.

\section{REFERENCES}

1. Thiel V. Mechanisms and enzymes involved in SARS coronavirus genome expression. J Gen Virol 2003;84:2305-15.

2. Menon JC, Rakesh PS, John D, Thachathodiyl D, Banerjee A. What was right about Kerala's response to the COVID-19 pandemic. BMJ Global Health 2020;5:e003212.

3. Weiss SR, Navas MS. Coronavirus pathogenesis and the emerging pathogen severe acute respiratory syndrome coronavirus. Microbiol Mol Biol Rev 2005;69:635-64.

4. Vijaykrishna D, Smith GJ, Zhang JX, Peiris JS, Chen H, Guan Y. Evolutionary insights into the ecology of coronaviruses. J Virol 2007;81:4012-20.

5. Gouilh MA, Puechmaille SJ, Gonzalez JP, Teeling E, Kittayapong $\mathrm{P}$, Manuguerra JC. SARS-coronavirus ancestor's footprints in South-East Asian bat colonies and the refuge theory. Infect Genet Evol 2011;11:1690-702.

6. Lawrence CM, Menon S, Eilers BJ, Bothner B, Khayat R, Douglas $\mathrm{T}$, et al. Structural and functional studies of archaeal viruses. J Biol Chem 2009;284:12599-603.

7. Kahn JS, McIntosh K. History and recent advances in coronavirus discovery. Pediatr Infect Dis J 2005;24:S223-7, S226.

8. Dos Santos WG. Natural history of COVID-19 and current knowledge on therapeutic treatment options. Biomed Pharmacother 2020;129:110493.

9. Sreeja N, Muthukumar M, Latha SM. Assessment on the impact of Covid-19 pandemic on fear and socioeconomic status among south Indian population. Int J Pharm Pharm Sci 2020;12:52-6.

10. Lai MM, Cavanagh D. The molecular biology of coronaviruses. Adv Virus Res 1997;48:1-100.

11. Vijgen L, Keyaerts E, Moes E, Thoelen I, Wollants E, Lemey P, et al. Complete genomic sequence of human coronavirus OC43: molecular clock analysis suggests a relatively recent zoonotic coronavirus transmission event. J Virol 2005;79:1595-604.

12. Mason RJ. Pathogenesis of COVID-19 from a cell biology perspective. Eur Respir J 2020;55:2000607.

13. Niharika D, B Niharika, T Aishwarya, A Nikitha, R Butool, M Ibrahim, et al. Coronavirus-a virus in learning. Int J Curr Pharm Res 2020;12:7-10.

14. Fung To S, Liu Ding X. Coronavirus infection, ER stress, apoptosis, and innate immunity. Front Microbiol 2014;5:296.

15. Edwards RA, Rohwer F. Viral metagenomics. Nat Rev Microbiol 2005;1:504-10.

16. De CE. Potential antivirals and antiviral strategies against SARS coronavirus infections. Expert Rev Anti Infect Ther 2006;4:291-302.

17. Lau AC, So LK, Miu FP, Yung RW, Poon E, Cheung TM, et al. Outcome of coronavirus-associated severe acute respiratory syndrome using a standard treatment protocol. Respirology 2004;9:173-83. 
18. Elston DM. COVID, Biologics, and psoriasis therapy. J Am Acad Dermatol 2020;83:1577-8.

19. Beigel JH, Tomashek KM, Dodd LE, Mehta AK, Zingman BS, Kalil AC, et al. Remdesivir for the treatment of covid-19-final report. N Engl J Med 2020;383:1813-26.

20. Joicy J, Johnson VB, Bharat M. Convalescent plasma therapy: a novel approach to a novel coronavirus. Int J Pharm Pharm Sci 2020;12:180-2.

21. Xuelin S, Shaoqiang Li, Kexin Li, Xin Hu. Pharmaceutical care of chloroquine phosphate in elderly patients with coronavirus pneumonia (COVID-19), Aging Medicine 2020;3:98-101.

22. Paula MS, Nathane SF, Pedro LS, Chiara R, Denise B, Paolo P. Pros and cons of corticosteroid therapy for COVID-19 patients. Respir Physiol Neurobiol 2020;280:103492.

23. Ambrish S. Drug targets for COVID-19 therapeutics: ongoing global efforts. J Biosci 2020;45:87.

24. Reza KK, Mohammad KK, Alireza N. COVID-19 target: a specific target for novel coronavirus detection. Gene Reports 2020;20:100740.

25. Carmen G, Tiziana G, Vanesa N, Jesus U. COVID-19: drug targets and potential treatments. J Med Chem 2020;63:12359-86.

26. Yahira MB Santos, Sarah EJ, Andrew DM. The SARS-coronavirus papain-like protease: structure, function, and inhibition by designed antiviral compounds. Antiviral Res 2015;115:21-38.

27. Lin MH, Moses DC, Hsieh CH, Cheng SC, Chen YH, Sun CY, et al. Disulfiram can inhibit MERS and SARS coronavirus papain-like proteases via different modes. Antiviral Res 2018;150:155-63.

28. Thanigaimalai P, Manoj M, Vigneshwaran N, Yoshio H, Sang HJ. An overview of severe acute respiratory syndromecoronavirus (SARS-CoV) 3CL protease inhibitors: peptidomimetics and small molecule chemotherapy. J Med Chem 2016;59:6595-628.

29. Douangamath A, Fearon D, Gehrtz P, Krojer T, Lukacik P, Owen $\mathrm{CD}$, et al. Crystallographic and electrophilic fragment screening of the SARS-CoV-2 main protease. Nat Commun 2020;11:5047.

30. Lee CC, Kuo CJ, Hsu MF, Liang PH, Fang JM, Shie JJ, Wang AH. Structural basis of mercury-and zinc-conjugated complexes as SARS-CoV 3C-like protease inhibitors. FEBS Lett 2007;581:5454-8.

31. Zhang L, Lin D, Sun X, Curth U, Drosten C, Sauerhering L, et al. Crystal structure of SARS-CoV-2 main protease provides a basis for the design of improved $\alpha$-ketoamide inhibitors. Science 2020;368:409-12.

32. Aftab SO, Ghouri MZ, Masood MU. Analysis of SARS-CoV-2 RNAdependent RNA polymerase as a potential therapeutic drug target using a computational approach.J Transl Med 2020;18:275.

33. Yin W, Mao C, Luan X, Shen DD, Shen Q, Su H, et al. Structural basis for inhibition of the RNA-dependent RNA polymerase from SARS-CoV-2 by remdesivir. Science 2020;368:1499-504.

34. Kirchdoerfer RN, Ward AB. Structure of the SARS-CoV nsp12 polymerase bound to nsp7 and nsp8 co-factors. Nat Commun 2019;10:2342.

35. Francis JB, Hind SA, Waad MAO, Abdallah MI, Noor B, Mohammed S, et al. State-of-the-art tools unveil potent drug targets amongst clinically approved drugs to inhibit helicase in SARS-CoV-2. Arch Med Sci 2020;16:508-18.

36. Viswanathan T, Arya S, Chan SH. Structural basis of RNA cap modification by SARS-CoV-2. Nat Commun 2020;11:3718.

37. Suranga LS. Overcoming nonstructural protein 15-nidoviral uridylate-specific endoribonuclease (nsp15/NendoU) activity of SARS-CoV-2. Future Drug Discovery 2020;2:FDD42.

38. Rosas Lemus M, Minasov G, Shuvalova L, Inniss NL, Kiryukhina 0 , Brunzelle J, et al. High-resolution structures of the SARSCoV-2 2'-0-methyltransferase reveal strategies for structurebased inhibitor design. Sci Signal 2020;13:eabe1202.

39. Hänel K, Stangler T, Stoldt M, Willbold D. Solution structure of the X4 protein coded by the SARS-related coronavirus reveals an immunoglobulin-like fold and suggests a binding activity to integrin I domains. J Biomed Sci 2006;13:281-93.

40. Wu K, Peng G, Wilken M, Geraghty RJ, Li F. Mechanisms of host receptor adaptation by severe acute respiratory syndrome coronavirus. J Biol Chem 2012;287:8904-11.
41. Surya W, Li Y, Torres J. Structural model of the SARS coronavirus E channel in LMPG micelles. Biochim Biophys Acta Biomembr 2018;1860:1309-17.

42. Huang Q, Yu L, Petros AM, Gunasekera A, Liu Z, Xu N, et al. Structure of the N-terminal RNA-binding domain of the SARS CoV nucleocapsid protein. Biochemistry 2004;43:6059-63.

43. Towler P, Staker B, Prasad SG, Menon S, Tang J. ACE2 X-ray structures reveal a large hinge-bending motion important for inhibitor binding and catalysis. J Biol Chem 2004;279:17996-8007.

44. Linda BB, Neeraj S, Eran E, Aleksandar S, Alan H, Rafael F. Targeting TMPRSS2 in SARS-CoV-2 infection. Mayo Clin Proc 2020;95:1989-99.

45. Giuseppe M. SARS-CoV-2 and COVID-19: what are our options? Where should we focus our attention on to find new drugs and strategies. Travel Med Infect Dis 2020;37:101685.

46. Dahms SO, Arciniega M, Steinmetzer T, Huber R, Than ME. Structure of the unliganded form of the proprotein convertase furin suggests activation by a substrate-induced mechanism. Proc Natl Acad Sci USA 2016;113:11196-201.

47. Li J, Zhu R, Chen K, Zheng H, Zhao H, Yuan C, et al. Potent and specific Atg8-targeting autophagy inhibitory peptides from giant ankyrins. Nat Chem Biol 2018;14:778-87.

48. Adithya J, Bhagyalakshmi N, Aishwarya S, Lekshmi RN. The plausible role of Indian traditional medicine in combating corona virus (SARS-CoV 2): a mini-review. Curr Pharm Biotechnol 2021;22:906-19.

49. Papia C. In silico investigation of phytoconstituents from Indian medicinal herb, 'Tinospora cordifolia (giloy)' against SARSCoV-2 (COVID-19) by molecular dynamics approach. J Biomol Struct Dyn 2020:1-18. DOI:10.1080/07391102.2020.1803968

50. Mansi P, N Latha. In silico studies reveal potential antiviral activity of phytochemicals from medicinal plants for the treatment of COVID-19 infection. 2020. DOI:10.21203/rs.3.rs$22687 / v 1$

51. Tregoning JS, Brown ES, Cheeseman HM, Flight KE, Higham SL, Lemm NM, et al. Vaccines for COVID-19. Clin Exp Immunol 2020;202:162-92.

52. Kaur SP, Gupta V. COVID-19 vaccine: a comprehensive status report. Virus Res 2020;288:198114.

53. Daniel ES, Martin FB. COVID-19: mechanisms of vaccination and immunity. Vaccines 2020;8:404.

54. Zhang Y, Gang Z, Hongxing P. Immunogenicity and safety of a SARS-CoV-2 inactivated vaccine in healthy adults aged 18-59 y: report of the randomized, double-blind, and placebo-controlled phase 2 clinical trial. medRxiv 2020. https://doi.org/10.1101/2020.07.31.20161216

55. Meo SA, Bukhari IA, Akram J, Meo AS, Klonoff DC. COVID-19 vaccines: comparison of biological, pharmacological characteristics and adverse effects of Pfizer/BioNTech and Moderna Vaccines. Eur Rev Med Pharmacol Sci 2021;25:1663-9.

56. Østergaard SD, Schmidt M, Horvath Puho E, Thomsen RW, Sørensen HT. Thromboembolism and the oxford-astrazeneca COVID-19 vaccine: side-effect or coincidence. Lancet 2021;397:1441-3.

57. AG Al Sehemi, Olotu FA, Dev S, Pannipara M, Soliman, Bijo M. Natural products database screening for the discovery of naturally occurring SARS-Cov-2 spike glycoprotein blockers. Chem Select 2020;5:13309-17.

58. Bilha B, Aswathy RD, Bhagyalakshmi N, Lekshmi RN. The impetus of COVID-19 in multiple organ affliction apart from respiratory infection: pathogenesis, diagnostic measure $s$ and current treatment strategy. Infect Disord Drug Targets 2020;20:1-13.

59. Matta S, Rajpal S, Chopra KK, Arora VK. Covid-19 vaccines and new mutant strains impacting the pandemic. Indian J Tuberc 2021;68:171-3.

60. Conti P, Caraffa A, Gallenga CE, Kritas SK, Frydas I, et al. The British variant of the new coronavirus-19 (Sars-Cov-2) should not create a vaccine problem. J Biol Regul Homeost Agents 2021;35:1-4.

61. Shanker M, Sanjay R, KK Chopra, VK Arora. Covid-19 vaccines and new mutant strains impacting the pandemic. Indian J Tuberc 2021;68:171-3. 